\title{
Finanças conjugais, desigualdades de género e bem-estar: Facetas de um Portugal em crise
}

Joint Income, Gender Inequalities and Well-being. Aspects of Portugal in Crisis Finances conjugales, inégalités de genre et bien-être. Facettes d'un Portugal en crise

Lina Coelho

\section{(2) OpenEdition}

\section{Journals}

\section{Edição electrónica}

URL: http://journals.openedition.org/rccs/6461

DOI: $10.4000 /$ rccs.6461

ISSN: 2182-7435

\section{Editora}

Centro de Estudos Sociais da Universidade de Coimbra

Edição impressa

Data de publição: 1 dezembro 2016

Paginação: 59-80

ISSN: 0254-1106

\section{Refêrencia eletrónica}

Lina Coelho, «Finanças conjugais, desigualdades de género e bem-estar: Facetas de um Portugal em crise », Revista Crítica de Ciências Sociais [Online], 111 | 2016, posto online no dia 07 dezembro 2016 consultado o 14 novembro 2019. URL : http://journals.openedition.org/rccs/6461 ; DOI : 10.4000/ rccs. 6461 


\section{LINA COELHO}

\section{Finanças conjugais, desigualdades de género e bem-estar Facetas de um Portugal em crise}

Os processos de controlo e gestão do dinheiro pelos casais e as suas implicações na alocação de recursos e bem-estar dentro da família constituem um objeto de pesquisa multidisciplinar a que tem sido dada muita atenção nas últimas décadas, sobretudo nos países anglo-saxónicos. A literatura evidencia que este é um domínio da vida familiar onde se manifestam, de forma privilegiada, desigualdades de género. Este artigo carateriza genericamente o tema e os resultados da investigação disponíveis na literatura, bem como as suas lacunas e limitações metodológicas. A realidade portuguesa é também brevemente caraterizada, com base nos resultados de um projeto de pesquisa recente, no âmbito do qual foram estudados os efeitos da austeridade sobre múltiplos aspetos da vivência familiar, incluindo o bem-estar material e emocional dos homens e das mulheres.

Palavras-chave: austeridade; bem-estar; desigualdade sexual; gestão financeira; Portugal; vida familiar.

\section{A problemática: dinheiro, género e família}

A decisão económica intrafamiliar desafia os fundamentos da ciência económica, ao questionar algumas das suas categorias analíticas de referência. Assim é, desde logo, no que respeita à versão estilizada do humano na qual assenta boa parte do discurso económico - o bomo economicus - indivíduo dotado de racionalidade cartesiana, perfeitamente informado, só e desapegado dos demais, cujo propósito é maximizar o interesse próprio, expresso na obtenção da maior quantidade de bens com o menor dispêndio de recursos. Esta ficção sobre o comportamento humano retrata mal a experiência das pessoas concretas, que vivem as suas vidas como pessoas-em-relação (Nelson, 1996) e cujas decisões são frequentemente ditadas por interesses compartilhados ou altruístas. Assim é também no contexto da família, onde pessoas fortemente vinculadas por laços, baseados no afeto e na intimidade, constrangem voluntariamente as suas decisões, ainda que não anulando a sua 
individualidade. A família é, pois, uma entidade muito diversa do postulado económico, de matriz neoclássica, segundo o qual se trata de uma unidade orgânica, de indivíduos com interesses uníssonos, que tomam decisões como que por consenso (Coelho, 2010). De facto, quando um casal se constitui num agregado doméstico, a lógica do interesse puramente individual tem de ceder o passo à lógica do interesse conjunto. Comungar mesa e habitação obriga a múltiplas decisões de natureza económica, com graus de complexidade diversos: organizar tempos de trabalho, dentro e fora de casa, e tempos de lazer, administrar o rendimento, decidir a estrutura da despesa para diferentes horizontes temporais (curto, médio e longo prazos), decidir eventuais poupanças ou empréstimos e sua aplicação... No contexto da relação conjugal, é expectável que as decisões sejam facilitadas por desejos e valores individuais em grande medida coincidentes e por uma particular propensão para a cooperação, determinada pela vontade de preservar a relação e a sua qualidade (Kirchler et al., 2001a). Mas tal não significa a dissolução do interesse próprio, nem o desaparecimento de motivações e perceções individuais diversas, geradoras de diferenças de opinião, que eventualmente conduzem a desacordo e conflito. Nesse caso, a decisão resulta de um processo negocial particular, um "conflito cooperativo", em que se manifesta a agência individual, fundada no bem-estar próprio mas, também, nas perceções acerca dos interesses, contribuições e legitimidade de cada pessoa que constitui a família (Sen, 1990).

O modo como cada pessoa percebe os seus interesses, bem-estar, obrigações e legitimidade dos comportamentos é resultado de identidades múltiplas associadas ao sexo, à classe social, à situação socioprofissional, à raça e à comunidade a que se pertence mas, também, à posição dentro da família (ibidem). Estes vários fatores de diferenciação social interagem de modo complexo para criar sistemas de discriminação que estruturam as relações de poder e subordinação, determinando a experiência concreta de vida para diferentes grupos de pessoas, como enfatiza a teoria feminista da interseccionalidade (Crenshaw, 1989).

Por outro lado, diversamente do que postula a teoria económica, o dinheiro não é nem fungível nem socialmente neutro, estando impregnado de múltiplas diferenciações sociais e adquirindo significados diversos em função da sua origem, dos usos que dele são feitos e da pessoa a quem é reconhecida legitimidade para o usar (Zelizer, 1994). As práticas de gestão do dinheiro na família são, então, determinadas por valores e normas sociais relativos à classe social, à idade e ao sexo. E, embora o dinheiro signifique poder, prestígio e sucesso para qualquer pessoa, "o rendimento das mulheres não parece conceder na família benefícios iguais ao rendimento dos 
homens" (Atwood, 2012: 7). Enquanto fonte mais direta e evidente do poder para o homem, o dinheiro tende a reproduzir o género (Deutsch et al., 2003).

Os progressos em matéria de igualdade, equidade distributiva e liberdade individual não eliminaram a segregação sexual do trabalho nem as desigualdades de género no acesso a recursos económicos ou na capacidade para influenciar as decisões familiares (Gershuny e Kan, 2012; Pahl, 1995; Sonnenberg, 2008; Vogler et al., 2008b). Ainda que se tenha vindo a ampliar o acesso das mulheres a um rendimento próprio, através da participação no mercado de trabalho, e os casais optem progressivamente por formas mais igualitárias de gestão de rendimentos, os homens continuam a deter mais poder nas decisões financeiras importantes tendo, em geral, a palavra final (Pahl, 1995; Vogler e Pahl, 1994). E, uma vez que o rendimento recebido diretamente pelas mulheres é, em média, menor do que o recebido pelos homens (Daly e Rake, 2003; Coelho, 2010), na ausência de uma redistribuição equitativa, elas usufruirão de menor bem-estar material do que os seus companheiros masculinos. Acresce que, sendo os custos com as crianças desproporcionalmente suportados pelas mulheres, de acordo com os papéis tradicionais de género (Pahl, 2005, 2008), a maternidade tende a agravar a desigualdade ao determinar quebras de rendimento para as mães (Waldfogel, 1998), em simultâneo com despesas acrescidas.

Este artigo aborda a gestão das finanças familiares numa perspetiva multidisciplinar. A primeira parte do texto carateriza genericamente a problemática e os resultados da investigação, bem como suas lacunas e limitações metodológicas. A segunda parte é dedicada à realidade portuguesa, dando destaque aos resultados de um projeto de pesquisa recente sobre o tema.

\section{A gestão financeira intrafamiliar}

A investigação neste domínio tem um caráter eminentemente multidisciplinar, recorrendo a múltiplas metodologias, de natureza quantitativa e qualitativa. A principal temática abordada tem sido a gestão intrafamiliar do dinheiro e seus beneficiários, com foco nos casais heterossexuais em famílias nucleares. Enquanto a investigação económica tem privilegiado a análise dos resultados da distribuição intrafamiliar dos recursos sobre o bem-estar material dos membros da família, a sociologia e a psicologia económica têm-se focado nos processos de controlo e gestão do dinheiro (Bonke 2015; Bennett, 2013) e nas suas implicações no bem-estar conjugal e familiar.

A influência da partição do rendimento entre os cônjuges sobre a alocação intrafamiliar da despesa tem sido estudada sobretudo com recurso a metodologias quantitativas, nomeadamente econométricas, aplicadas a bases de dados sobre rendimentos e despesas das famílias. Os resultados mostram 
que os padrões de despesa dependem da titularidade do rendimento (Hoddinott e Haddad, 1995; Lundberg et al., 1997; Phipps e Burton 1998; Thomas 1990) e apresentam, em geral, sintonia com as esferas de atuação tradicionais de cada sexo (por exemplo, as mulheres gastam relativamente mais com as crianças do que os homens). Mas este tipo de estudos enferma de uma vulnerabilidade metodológica assinalável, uma vez que poucos são os bens do cabaz de consumo familiar suscetíveis de atribuição aos membros da família em função do seu sexo e da sua idade (homem, mulher, crianças). Assim, as conclusões obtêm-se necessariamente a partir de um número restrito de bens e/ou de hipóteses mais ou menos hercúleas sobre os padrões de consumo (considerando, por exemplo, roupa de homem, tabaco, bebidas alcoólicas e jogos de azar como consumos masculinos e roupa feminina e infantil, brinquedos e educação como consumos femininos) (Bonke, 2015).

No que respeita aos processos de controlo e gestão do dinheiro no casal, a investigação tem mostrado a existência de relações entre os sistemas de organização adotados e o poder decisional dos cônjuges (Vogler e Pahl 1994; Pahl 2005; Vogler et al. 2008a, 2008b). Um instrumento de análise relevante nestes estudos é a tipologia proposta pela socióloga britânica Jan Pahl (1989), que contempla quatro principais modalidades de gestão e controlo do rendimento familiar. No sistema de gestão integral, um dos parceiros entrega o seu salário ao outro, geralmente reservando uma pequena parte para as suas despesas pessoais; o outro parceiro adiciona-lhe o seu eventual rendimento próprio, e é responsável pela gestão. No sistema de mesada para governo da casa, um dos parceiros decide o valor de uma mesada fixa, que dá ao outro para as despesas domésticas do dia a dia, e o rendimento restante é gerido por ele. $\mathrm{Na}$ gestão conjunta, o casal partilha todo (ou quase todo) o rendimento, tendo ambos idêntico acesso a ele e assumindo responsabilidade conjunta pela sua gestão. No sistema de gestão independente, cada parceiro obtém um rendimento próprio, que gere autonomamente, e cada um é responsável por diferentes categorias das despesas comuns. Ao combinar dados sobre o acesso ao dinheiro e a esfera de responsabilidade de cada cônjuge nas despesas familiares, estes estudos evidenciam um padrão complexo de interrelações entre modalidades de gestão, valor e titularidade do rendimento e poder de decisão dos membros do casal, comprovando também que esta esfera da vida familiar manifesta os papéis sociais de género (Pahl, 2007). Assim, a desigualdade de género tende a ser menos pronunciada em casais que gerem conjuntamente o dinheiro posto em comum e particularmente pronunciada nas famílias com controlo masculino das finanças (Pahl, 1989, 1995; Vogler e Pahl, 1994; Vogler, 1998; Vogler et al., 2006). E, embora larga maioria dos casais relate idêntico poder individual sobre as decisões financeiras e apenas 
uma minoria declare maior poder do homem (Vogler et al., 2008b; Vogler e Pahl, 1994; Woolley, 2003), as mulheres tendem a gerir quando o dinheiro é escasso, enquanto os homens tendem a fazê-lo quando o rendimento não coloca restrições (Vogler, 1998; Pahl, 1995). Mas a escolha da modalidade de gestão depende também de outros fatores, como sejam a relação com o mercado de trabalho (se a mulher não tem atividade remunerada, tende a ser ela a responsável pela gestão, sob controlo masculino); a escolaridade (maior escolaridade aumenta a probabilidade de partilha de recursos e responsabilidades); as representações sociais sobre género (ideologia tradicional, em que o homem é visto como o provedor de sustento, aumenta a probabilidade de controlo pelo homem), casamento (comunhão e partilha favorecem a gestão conjunta, autonomia individual e igualitarismo favorecem a gestão independente) e família (incluindo a relevância atribuída aos filhos); a socialização parental (o sistema usado pelos pais influencia a opção); o tipo de família ou de relação conjugal (casais em união marital, casais sem filhos e famílias recompostas tendem à segregação de rendimentos e de esferas de despesa); e a fase no ciclo de vida (casais jovens sem filhos tendem para a independência, casais idosos para a partilha) (Anu, 2011; Burgoyne et al., 2007; Pahl, 1995, 2008; Singh e Morley, 2011; Vogler, 1998; Vogler et al., 2006; Vogler et al., 2008b; Vogler e Pahl, 1994).

A literatura mostra também que discordância de opiniões, e eventual conflito conjugal, ocorre sobretudo em torno da aquisição de bens ou serviços com caráter excecional e de maior valor (bens duradouros, férias, etc.). As decisões de despesa relativas à satisfação das necessidades diárias da família ocasionam menos divergência porque tendem a ser automáticas e ditadas pela rotina, envolvendo baixa reflexividade (Vogler et al., 2008b). Ou seja, enquanto as compras rotineiras e as compras por impulso são fundamentalmente decididas por uma só pessoa, norteada por scripts ${ }^{1}$ cognitivos, as decisões de compra de bens mais valiosos ou com maior visibilidade social costumam envolver todos os atores a que dizem respeito, requerendo processos de decisão mais longos e ponderados e não envolvendo scripts cognitivos, pelo que facilmente abrem espaço a diferenças de opinião (Kirchler et al., 2001; Kirchler et al., 2016). Estas são decisões que ocorrem ao longo de um processo interativo com várias etapas, distribuídas por períodos de tempo mais ou menos longos, e num contexto complexo, onde as tarefas do quotidiano se entrelaçam com decisões de natureza financeira e não financeira (trabalho doméstico e não

\footnotetext{
${ }^{1}$ O conceito de script surgiu na literatura significando "uma sequência pré-determinada e estereotipada de ações que definem uma situação bem conhecida" (Schank e Abelson, 1975). Trata-se, portanto, de um roteiro comportamental, baseado nos valores e representações sociais prevalecentes numa dada cultura, que orientam a atuação das pessoas em situações habituais.
} 
doméstico, filhos, lazer e a própria relação). A história específica de cada relação é também importante, uma vez que os resultados dos processos decisórios passados tendem a determinar a solução do processo decisional presente: se um parceiro exerceu maior influência e beneficiou mais em decisões passadas, é mais provável que o outro parceiro obtenha ascendente e vantagem no resultado do desacordo presente (Kirchler et al., 2001).

A decisão económica e financeira intrafamiliar é pois um processo complexo, que ocorre num contexto sociocultural específico, em formações familiares diversas, relações conjugais com uma história particular e envolvendo pessoas com personalidades próprias. Desta complexidade decorrem desafios metodológicos significativos (Bennett, 2013; Kirchler et al., 2001, Kirchler et al., 2016). Os dados utilizados na pesquisa provêm geralmente de inquérito ou entrevista, sendo que, em qualquer dos casos, os métodos de entrevista são críticos (Cantillon, 2013; Nyman et al., 2013). Na medida em que "as práticas financeiras dos casais são tão secretas como as suas vidas sexuais” (Pahl, 2000), este é um assunto difícil de abordar para os entrevistados, que podem reagir à observação externa (dos entrevistadores) fornecendo informação falsa ou desvirtuada (Kirchler et al., 2001). Por outro lado, se apenas um dos cônjuges é inquirido, podem obter-se resultados enviesados (Cantillon, 2013), porque há o risco de "o homem e a mulher representarem famílias diferentes” (Vogler et al., 2008a). De facto, registam-se com frequência respostas contraditórias ou diversas dos cônjuges, quando ambos são inquiridos separadamente (Bennett et al., 2010). Assim, combinar informação quantitativa recolhida ao nível individual e ao nível da família (tipicamente através da pessoa que se assume como sua 'representante') pode tornar-se difícil (Ashby e Burgoyne, 2008; Bennett, 2013; Evertsson e Nyman, 2012; Coelho, 2013). Em todo o caso, a informação em larga escala é escassa porque os inquéritos oficiais raramente contemplam o plano intrafamiliar, assumindo geralmente a leitura da família como unidade de decisão económica. Por outro lado, mesmo quando a realidade intrafamiliar é tida em conta, os inquéritos são em geral pontuais, não permitindo o acompanhamento da dinâmica familiar ao longo do tempo.

Os registos por diário, de que é exemplo o Estudo por Diário de Viena (Kirchler et al., 2001; Kirchler et al., 2016), constituem uma alternativa metodológica interessante porque a recolha de informação é obtida por autorrelato diário de cada cônjuge, minorando a interferência externa do entrevistador. Contudo, este método não evita as leituras subjetivas dos cônjuges sobre uma mesma realidade: cerca de um terço dos relatos individuais sobre as discussões do casal mostraram-se diversos, muitas vezes em conformidade com estereótipos socialmente desejáveis, no sentido em 
que a influência e o benefício próprios tendem a ser subestimados em favor da influência e do benefício do parceiro. A interferência da desejabilidade social nas respostas é, aliás, um problema a ter em conta, qualquer que seja o método de recolha da informação (Bennett, 2013).

A própria definição do objeto de estudo - dominada pelo casal heterossexual, em idade ativa - é limitadora (ibidem). ${ }^{2}$ Refira-se, por exemplo, que muita da pesquisa se tem debruçado sobre casais com filhos, sem que o papel destes enquanto agentes na decisão seja tido em conta. A sua influência é, deste modo, invisibilizada, facto particularmente relevante quando se estudam sociedades onde os jovens adultos permanecem mais tempo em casa dos pais (como no sul e leste europeus) ${ }^{3}$ ou retornam por períodos longos (ibidem). A omissão das famílias alargadas constitui também uma limitação, dado que a gestão do orçamento comum deste tipo de famílias envolve complexidades acrescidas (Coelho e Ferreira-Valente, 2016).

\section{A gestão financeira intrafamiliar em Portugal}

O modo como os casais gerem o seu dinheiro tem sido escassamente investigado em Portugal. Um primeiro estudo qualitativo sobre o tema (Gomes, 2000) concluiu que a maioria dos casais portugueses partilha, em alguma medida, recursos e decisões, ainda que as modalidades da partilha dependam de fatores múltiplos (rendimento, fase no ciclo de vida, caraterísticas individuais, conveniência prática, representações sociais de género, geração de pertença, organização familiar). Assim, por exemplo, casais mais velhos gerem o dinheiro de forma mais partilhada do que casais jovens ou pertencentes a famílias recompostas. $\mathrm{O}$ estudo identificou também diferenciações de género nos padrões de despesa, com as mulheres a assumirem mais as despesas domésticas e quotidianas (alimentação, limpeza, vestuário) e os homens as despesas relacionadas com a habitação (renda ou prestação de empréstimo; água, eletricidade, gás, telefone).

Os discursos e representações sobre a divisão das tarefas familiares também têm sido objeto de pesquisa. Resultados de dois estudos quantitativos por inquérito (Poeschl, 2000) evidenciaram esferas de decisão em função do género, atribuindo aos homens maior poder de decisão sobre o orçamento familiar e o lazer, e às mulheres maior influência em decisões relacionadas com os filhos e com a casa. Mais recentemente, a relação de poder no casal foi estudada através dos comportamentos considerados apropriados em

\footnotetext{
${ }^{2}$ Entre os trabalhos que procuram superar esta limitação podem referir-se alguns que se focam nos casais mais velhos (Lundberg et al., 2003) ou nos casais homossexuais (Burgoyne et al., 2011; Evertsson e Nyman, 2012).

${ }^{3}$ Veja-se, a propósito, Iacovou e Skew (2011).
} 
caso de desacordo. Concluiu-se que as estratégias de influência brandas são vistas como as mais frequentemente utilizadas pelos cônjuges, para não danificar a relação. Todavia, os resultados deixaram transparecer relações de poder assimétricas, dado que, no caso de um igual esforço dos cônjuges para impor a sua decisão, o marido foi considerado como tendo a última palavra (Poeschl, 2016).

O módulo anual especializado de 2010 do Inquérito Europeu às Condições de Vida e Rendimento (EU-SILC) recolheu informação sobre partilha de recursos e poder de decisão em matéria financeira nas famílias da União Europeia, incluindo Portugal. A análise realizada por Nagy et al. (2012) mostra que a maioria dos casais (75\%) junta os rendimentos e trata-os como recurso comum, ainda que haja gradações por país, com Estónia, Finlândia e Áustria a apresentarem valores inferiores a 60\% e Grécia, Hungria, Roménia e Malta valores superiores a $85 \%$. Portugal situa-se na média. Quando interrogados sobre o parceiro que tem a última palavra nas decisões importantes, cerca de $79 \%$ dos europeus, homens e mulheres, declararam distribuição igualitária. Os valores para Portugal são cerca de 6 pontos percentuais inferiores e apresentam um desvio de 8 pontos percentuais a favor dos homens.

No âmbito do projeto "FINFAM - Finanças, género e poder: como estão as famílias portuguesas a gerir as suas finanças no contexto da crise?" (2013-2015) aprofundou-se a análise daqueles mesmos dados para o caso português, com recurso à tipologia de gestão financeira familiar acima referida (Pahl, 1989, 1995, 2008; Vogler e Pahl, 1993, 1994). Foi estimada a prevalência de cada modalidade de gestão e a sua relação com um conjunto de caraterísticas sociodemográficas, familiares e económicas dos casais (Coelho, 2013; Coelho e Ferreira-Valente, 2016). Em geral, os resultados encontrados confirmam as regularidades patentes na literatura: a maioria dos casais portugueses $(64,5 \%)$ junta os rendimentos, tratando-os como recurso comum e gerindo-os, pelo menos parcialmente, em conjunto; quase $30 \%$ dos casais usa o sistema de gestão integral, pela mulher (10,7\%) ou pelo marido $(18,9 \%)$; e apenas uma minoria usa a modalidade de mesada para governo da casa $(3,2 \%)$ ou a gestão independente (2,8\%). É de assinalar que, em cerca de um terço dos casais, se registaram inconsistências entre as respostas do cônjuge que respondeu ao inquérito enquanto representante da família e as respostas individuais de cada cônjuge, confirmando uma dificuldade metodológica já assinalada na literatura (Ashby e Burgoyne, 2008; Bennett, 2013; Evertsson e Nyman, 2012; Kirchler et al., 2001).

O estudo quantitativo das correlações entre os sistemas de gestão e as caraterísticas do casal e respetivo agregado familiar permitiu também confirmar, para Portugal, um conjunto de regularidades conhecidas (Ashby 
e Burgoyne, 2008; Burgoyne et al. 2007; Heimdal e Houseknecht, 2003; Kenney, 2006; Martínez et al. 2004; Vogler et al. 2008a, 2008b; Laporte e Schellenberg, 2011; Ludwig-Mayerhofer et al. 2006; Vogler e Pahl, 1993). Assim, a gestão conjunta revelou-se mais comum entre os casais com filhos dependentes ou com rendimento por adulto equivalente acima da média e também naqueles com rendimentos individuais semelhantes ou rendimento masculino ligeiramente superior ao feminino. Por outro lado, esta modalidade de gestão revelou-se menos frequente em casais de formação recente e em famílias alargadas ou com filhos adultos. Nestes grupos, prevalecia a gestão conjunta parcial. Já a gestão independente era mais frequente em famílias recompostas, casais recentemente formados, em união de facto, ou vivendo em áreas urbanas. A gestão integral por um dos cônjuges e a mesada para governo da casa evidenciaram-se em casais idosos, eventualmente inseridos em famílias alargadas, e naqueles com maiores diferenciais de rendimento individual.

No âmbito do projeto FINFAM foi realizado um outro inquérito por questionário, ${ }^{4}$ a uma amostra tendencialmente representativa dos casais portugueses entre 30 e 50 anos de idade, com filhos dependentes, visando validar os resultados já obtidos e identificar os efeitos da crise económica nas vivências e práticas familiares, incluindo no domínio da gestão financeira. A informação obtida por inquérito foi complementada por um conjunto de 42 entrevistas diádicas a casais, com o objetivo de aprofundar a análise dos processos de ajustamento impostos pela austeridade e suas repercussões no bem-estar individual e familiar. ${ }^{5}$ Foi dada particular atenção a eventuais implicações diferenciadas para homens e mulheres. Os resultados confirmaram genericamente as conclusões do estudo anterior sobre as práticas de gestão do dinheiro, ainda que com diferenças de proporção, eventualmente explicáveis pela diferente composição das amostras estudadas (Ferreira-Valente e Coelho, 2015a). No que respeita às implicações da austeridade, apresentam-se nos pontos seguintes, de forma muito sumária, alguns dos resultados obtidos.

\section{Finanças conjugais, género e bem-estar no contexto da crise em Portugal}

A gestão financeira da família é fortemente determinada por fatores contextuais, de natureza social, cultural e económica, que estabelecem o quadro geral das condições de vida numa dada sociedade. Nos últimos anos,

\footnotetext{
${ }^{4}$ Uma abordagem detalhada do método utilizado e das conclusões gerais pode ser encontrada em Ferreira-Valente e Coelho (2015a).

${ }^{5}$ As entrevistas, semiestruturadas, foram aplicadas a ambos os membros do casal, em simultâneo. A amostra é diversificada, incluindo pessoas entre 27 e 53 anos e com tempos de coabitação entre 1 e 29 anos. O nível de escolaridade era inferior ao ensino secundário para $50 \%$ dos homens e $32,5 \%$ das mulheres. Incluem-se famílias urbanas e rurais de 19 concelhos, incluindo Coimbra, Lisboa, Porto, Portalegre e respetivas áreas limítrofes.
} 
os governos europeus adotaram programas de austeridade, particularmente intensos nos países afetados pela crise das dívidas soberanas, incluindo Portugal, donde resultaram regressões pronunciadas do nível de vida e do emprego e empobrecimento generalizado. Importa pois analisar de que modo este contexto se repercutiu no quotidiano das famílias.

No âmbito do Programa de Assistência Económica e Financeira 2011-2014, acordado entre o governo português e uma troika de instituições internacionais (Fundo Monetário Internacional, Comissão Europeia e Banco Central Europeu), foi aplicado um vasto conjunto de medidas de austeridade (aumento dos impostos, redução de funcionários públicos e dos respetivos salários, cortes nas pensões e noutros benefícios sociais - subsídio de desemprego, abono de família, subsídio social de inserção) e reformas institucionais (revisão da lei laboral visando a facilitação dos despedimentos e a flexibilização do mercado de trabalho, privatização e concessão da exploração a privados de serviços ou empresas públicas, etc.) com o objetivo de promover o rápido saneamento das contas públicas e reforçar a competitividade externa da economia. ${ }^{6} \mathrm{~A}$ consequente diminuição generalizada dos rendimentos, a par do aumento dos encargos familiares, obrigou a maioria das famílias à adoção de medidas de adaptação orçamental (Frade e Coelho, 2015; Ribeiro et al., 2015a; SEDES, 2012) que podem influenciar os modos de gestão financeira intrafamiliar. Por outro lado, a redução dos níveis de bem-estar material tende a provocar deterioração do bem-estar psicológico dos indivíduos e degradação da qualidade das relações familiares (American Psychological Association, 2015). A literatura documenta também que as crises económicas produzem efeitos diferenciados para homens e mulheres, agravando desigualdades, quer na esfera pública, nomeadamente no mercado de trabalho, quer na esfera privada, nomeadamente na repartição do trabalho não remunerado e do bem-estar (Ferreira, 2014; Gálvez e Rodríguez-Modroño, 2012, 2016; Elson, 2014; Karamessini e Rubery, 2014).

\section{Austeridade, escassez e perdas de bem-estar}

As famílias em idade ativa com filhos foram auscultadas, através do inquérito, acerca dos impactos da crise nos seus rendimentos, despesas e situação laboral. Os resultados, sumariados nos quadros 1 e 2 , revelam a redução dos orçamentos familiares para mais de dois terços das famílias, a par com a necessidade de recurso a poupanças passadas para suprir necessidades correntes

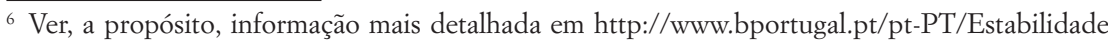
Financeira/OProgramaAssistenciaFinanceiraPortugal/Paginas/PAEFemonitorizacaopos programa.aspx, consultado a 24.05.2016.
} 
$(50,7 \%)$ e a cortes generalizados nas despesas, ainda que afetando sobretudo as componentes habitualmente vistas como não essenciais (restaurantes, férias e lazer, eletrodomésticos e mobiliário, roupa, serviços de apoio doméstico) (Frade e Coelho, 2015).

QUADRO 1 - Impactos da crise na vida dos casais com filhos

\begin{tabular}{lc}
\hline Impactos & \% de famílias \\
\hline Redução do orçamento familiar & 67,3 \\
\hline Redução do valor das poupanças & 62,4 \\
\hline Utilização de poupanças para pagar despesas correntes & 50,7 \\
\hline Cortes salariais & 37,4 \\
\hline Aumento do horário de trabalho & 27,7 \\
\hline Desemprego & 15,3 \\
\hline
\end{tabular}

QUADRO 2 - Cortes nas despesas familiares 2010-2014

\begin{tabular}{ll}
\hline Tipos de despesa & $\%$ de famílias* \\
\hline Restaurantes & 84,3 \\
\hline Férias e viagens & 79,5 \\
\hline Outras atividades de lazer & 77,4 \\
\hline Eletrodomésticos e mobiliário & 66,0 \\
\hline Vestuário & 65,4 \\
\hline Serviços domésticos & 54,4 \\
\hline Apoio a pessoas dependentes & 44,4 \\
\hline Transportes e combustíveis & 37,4 \\
\hline Telefone e internet & 37,1 \\
\hline Seguros & 29,0 \\
\hline Alimentação & 23,3 \\
\hline Eletricidade, gás e água & 19,7 \\
\hline Saúde & 13,5 \\
\hline Educação dos filhos & 12,3 \\
\hline * os valores percentuais foram calculados tomando como referência o número total de famílias \\
inquiridas que incorriam em cada tipo de despesa em 2010 (e não a totalidade da amostra).
\end{tabular}


Como já referido, as tensões devidas a problemas económico-financeiros têm vindo a ser relacionadas com diversos sintomas psicológicos negativos (Madianos et al., 2011; Vinokur et al., 1996) e aumento dos conflitos conjugais (Conger et al., 1999; Gudmunson et al., 2007). Os dados do quadro seguinte indiciam alguns efeitos desta natureza nas pessoas inquiridas.

QUADRO 3 - Incidência de efeitos psicológicos negativos e conflitualidade conjugal

\begin{tabular}{lc}
\hline Impactos & $\%$ de famílias \\
\hline $\begin{array}{l}\text { Procurar mais vezes o médico ou outro profissional por problemas } \\
\text { emocionais, de ansiedade, ou insónias }\end{array}$ & 29,2 \\
\hline $\begin{array}{l}\text { Aumentar a toma de medicamentos ou outro(s) por problemas } \\
\text { emocionais, de ansiedade, ou insónias }\end{array}$ & 26,1 \\
\hline Sentir-se mais tenso/a ou nervoso/a do que antes & 24,4 \\
\hline Sentir menos prazer nas coisas de que costumava gostar & 18,7 \\
\hline Discussões conjugais mais frequentes & 27,0 \\
\hline Mais vezes em desacordo com o/a cônjuge por questões financeiras & 35,3 \\
\hline
\end{tabular}

Os impactos negativos no bem-estar emocional dos cônjuges e no seu relacionamento não são independentes das caraterísticas socioeconómicas das famílias (por exemplo, do rendimento mensal e da situação profissional) nem da intensidade das mudanças ocorridas na vida familiar durante a crise (Ribeiro et al., 2015b). O desemprego (especialmente se duplo ou masculino), a insuficiência ou quebra pronunciada (de $50 \%$ ou mais) do rendimento e o forte endividamento revelaram-se os fatores com mais consequências negativas no bem-estar emocional dos cônjuges e no aumento das discussões do casal. Concluiu-se também que a percentagem de famílias que reporta impactos psicossociais negativos aumenta com o número de alterações registadas nas suas práticas quotidianas sugerindo, assim, a importância do efeito cumulativo das alterações sofridas.

Pretendeu-se também saber se os ajustamentos na economia familiar provocaram alterações nas modalidades de gestão praticadas pelos casais, bem como as razões da eventual mudança. Dos 1001 casais abrangidos só 44 declararam ter alterado a forma de gerir o seu orçamento e apenas cerca de metade destes $(47 \%)$ em consequência direta ou indireta da crise (Ferreira-Valente e Coelho, 2015a). A austeridade vivida pelas famílias não se refletiu, pois, no imediato, nos modelos de gestão praticados pelos casais, o que corrobora resultados antes apresentados na literatura sobre a natureza 
notavelmente estável dos arranjos financeiros dos casais (Laurie e Gershuny, 2000), que tendem a só ser alterados em caso de mudanças fundamentais (como uma doença grave, por exemplo), num claro esforço para manter as práticas anteriores (Bisdee et al., 2013). Contudo, é de admitir que o prolongamento da austeridade (que parece não ter fim à vista em Portugal) acabe por produzir efeitos também nesta dimensão da vida conjugal, à medida que a aparente transitoriedade da crise adquira caráter crónico para as famílias mais duramente afetadas (em casos de desemprego de longa duração, precariedade laboral ou emigração forçada). Importa, pois, prolongar a investigação para além do horizonte temporal aqui considerado.

\section{Desigualdades de género no âmbito familiar}

A pesquisa procurou também compreender em que medida a gestão dos orçamentos familiares em Portugal manifesta desigualdades de género e o modo como estas poderão ter sido afetadas pela situação de austeridade.

Os dados recolhidos mostram que as mulheres continuam a dedicar mais tempo ao trabalho doméstico e ao cuidado com as crianças do que os seus parceiros masculinos, mesmo quando ambos trabalham a tempo inteiro (Ribeiro et al., 2015a). Os padrões de género na realização das tarefas domésticas também se mantêm (Perista, 2002; Poeschl, 2000), com as mulheres a desempenharem principalmente as tarefas mais rotineiras, mais exigentes em tempo e confinadas ao interior da casa (cuidar da roupa, cozinhar, limpar a casa, cuidar dos doentes) enquanto os homens predominam nas tarefas relativas a reparações, automóvel e algumas tarefas financeiras, como o pagamento das contas e dos impostos (Ribeiro et al., 2015a).

Embora a participação dos homens nas tarefas domésticas nunca exceda a das mulheres, o desemprego masculino reforça a participação masculina durante a semana, mas não ao fim de semana. Já o desemprego feminino conduz a um reforço do trabalho doméstico das mulheres, a todo o tempo. Ou seja, os homens desempregados continuam a dispor do fim de semana para descanso e para atividades de lazer, mas as mulheres desempregadas nunca se libertam das tarefas da família (ibidem).

No que respeita à divisão das tarefas financeiras, os resultados confirmam que o desemprego masculino parece tender a reduzir o papel dos homens na gestão do dinheiro (Afonso e Poeschl, 2006). Contudo, tal não significa necessariamente um aumento da autonomia de decisão das mulheres podendo, ao invés, representar uma carga acrescida de responsabilidade. $\mathrm{Na}$ medida em que o desemprego masculino produz cortes mais pronunciados no rendimento familiar do que o desemprego feminino, devido à disparidade salarial vigente (European Commission, 2014), gerir a escassez 
decorrente pode ser muito árduo e desgastante, deixando às mulheres a incumbência de 'fazer esticar o dinheiro' quando o rendimento não chega para pagar as contas (Thorne, 2010). A informação recolhida nas entrevistas parece suportar esta hipótese, como evidenciado nos dois extratos seguintes.

A [mulher] é que é a jogadora neste tabuleiro. [...] estes cortes todos, isto tudo... [...] A questão é que ela é que gere... Eu dou-lhe muito valor nisso porque é verdade. Às vezes, eu brinco... Pareces a "mulher elástica”. Como é que tu esticas daqui, pões para ali, etc. Eu não era capaz... Eu, às vezes, ‘apanho’ certas coisas e vejo a ginástica que ela tem de fazer, não é? As datas. É assim, não é só o pagar... é saber que tem de pagar naquela data e o que é que é para pagar naquela data. [...] Sim, a mim passa-me tudo ao lado. Eu só noto quando tenho falta de alguma coisa...

(António, 36 anos, vendedor, dois filhos, área urbana)

A mulher tem um encargo maior... Tem que gerir as despesas da casa...

(Florival, 52 anos, pedreiro, dois filhos, área rural)

As entrevistas sugerem também que as perdas de bem-estar individual e psicossocial induzidas pela crise foram distribuídas assimetricamente entre as mulheres e os homens. Por um lado confirma-se que alguns dos cortes mais acentuados nas despesas se repercutem no aumento do trabalho familiar não remunerado, maioritariamente assegurado pelas mulheres. É o caso do apoio a pessoas dependentes, serviços domésticos ou despesas com restaurantes (estes obrigando à preparação das refeições em casa, nomeadamente para rechear a lancheira que se leva para o emprego).

ELA: A parte económica o que é que faz? Nós deixámos de ter a senhora para ajudar na casa. Portanto, temos que compensar esse tempo que ela fazia... E quando? Nos dias em que podíamos ir dar uma volta, estar com os amigos... [...] Era uma ajuda muito boa. [...] Eu ganhava no tempo em que estava com os meninos. Que é isso que eu... acabo por ficar triste... Porque deito-os e penso assim... Fogo, hoje nem tive tempo de me sentar aqui a brincar um bocado com eles, só ao fim de semana, só ao fim de semana...

ELE: E ao fim de semana dizes... "vai chatear o teu pai!"

ELA: Vai chatear o teu pai que eu tenho de arrumar a casa, tenho roupa para lavar, para adiantar as coisas [...] Eu, por exemplo, ainda ontem [domingo]... já adiantei três almoços e um jantar. A gente gostava de ir comer fora...

ELE: Não há tempo assim como era antigamente...

(António, 36 anos, vendedor; Ana, 40 anos, técnica de informática; dois filhos, área urbana) 
Por outro lado, certos consumos pessoais tradicionalmente associados às mulheres (cabeleireiros, cosmética, etc.) sofreram reduções drásticas, quando não foram mesmo suprimidos.

Também mudei de cabeleireira... esta é mais baratinha. Eu gostava de ir a uma onde realmente gosto mais, mas os preços não são comportáveis. É claro, eu adorava andar no ginásio, mas não dá, não dá. Gostava de usar um creme de rosto um bocadinho melhor. Já vou para o mais barato, já vou para um supermercado quando antes comprava na farmácia, por exemplo. Isto são coisas que eles não têm tanta noção, não é? Os homens...

(Daniela, 43 anos, ajudante em lar de idosos, um filho, área urbana)

Alguns testemunhos sugerem ainda uma maior disponibilidade das mulheres para sacrificar os próprios consumos pessoais e recreativos. $\mathrm{O}$ seguinte excerto é especialmente ilustrativo.

ELE: Porque há uma coisa que eu não deixo de fazer que é... eu ter dinheiro para ir beber umas cervejas com os amigos, pá. [...] Porque eu preciso.

ELA: Pronto, eu já me retraio mais...

ELE: Eu não consigo. Porque, quer dizer, se não, o que é que andamos aqui a fazer? $[\ldots]$

ELA: Pronto, eu... eu agora já não compro roupa para mim, já é mais para o [nome do filho]... Pronto, as prioridades passaram a ser outras. Se calhar, não vou sair com as amigas, e jantamos antes em casa de uma de nós... E pronto, eu deixei de sair muito mais... o meu marido nem tanto, mas eu deixei de sair muito mais...

(Adelaide, 38 anos, funcionária pública; Adelino, 41 anos, eletricista; um filho, área urbana)

O reforço da carga de trabalho global, a redução dos tempos de descanso e lazer e o desgaste psicológico e emocional resultante da gestão da escassez (de tempo e dinheiro) são, assim, fatores que se combinam para degradar desproporcionalmente o bem-estar das mulheres no contexto da crise. Em nada surpreende, pois, a correlação negativa, obtida num estudo quantitativo, entre saúde física e mental e tempo dedicado ao trabalho doméstico (Ferreira-Valente e Coelho, 2015b). Esta é uma temática que carece de aprofundamento em estudos futuros.

\section{Considerações finais}

Este artigo procurou contribuir para a compreensão da gestão financeira intrafamiliar, em geral, e da realidade portuguesa, em particular. Atentando 
na situação de crise económica, foi dado destaque aos seus efeitos naquele domínio da vida familiar e suas consequências para o bem-estar dos membros da família, numa perspetiva de género.

Esta é uma agenda de investigação com ampla margem para desenvolvimentos futuros. O enfoque nos comportamentos dos casais heterossexuais em idade ativa, em famílias nucleares, deixa espaço em aberto para a investigação de outros tipos de família, noutras fases do ciclo de vida e atendendo a outras influências, que não apenas a dos parceiros conjugais. A investigação enfrenta, contudo, dificuldades metodológicas significativas, desde logo porque a realidade intrafamiliar é difícil de penetrar pelo investigador, que corre o risco de interferir no seu objeto analítico, obtendo resultados desvirtuados. Por outro lado, a influência de fatores de desejabilidade social nas respostas sobre a gestão financeira do casal é um problema de difícil superação.

Apesar das dificuldades, a investigação recente permitiu levantar a ponta do véu sobre este importante domínio da vida das famílias portuguesas. Os resultados mostram que os casais portugueses têm práticas de gestão do dinheiro em grande medida coincidentes com os seus congéneres de outros países ocidentais. No que respeita aos efeitos da austeridade, ela parece não ter produzido alterações nas práticas de gestão pré-existentes, sendo de admitir como justificativa a resistência dos casais a alterar um domínio fortemente estruturante da sua vivência conjunta, a menos que haja mudanças profundas ou definitivas na sua realidade objetiva. Na medida em que a crise seja encarada como perturbação transitória, os casais procurarão manter as práticas prévias, por forma a preservar os termos da sua relação.

$\mathrm{O}$ artigo permitiu evidenciar que o estilo de vida da generalidade das famílias foi fortemente penalizado pela crise, que obrigou à degradação significativa dos seus padrões de consumo. Neste processo, o bem-estar material e emocional das mulheres parece ter sido mais sacrificado do que o dos homens, quer pelo agravamento da sobrecarga de tempos de trabalho e consequente sacrifício do lazer, quer pelo maior sacrifício dos seus consumos pessoais. As eventuais consequências desta situação para a qualidade das relações conjugais e familiares e o bem-estar das crianças são temas que carecem de aprofundamento em pesquisas futuras.

Revisto por Sofia Silva

\section{Referências bibliográficas}

Afonso, Rosa-Marina; Poeschl, Gabrielle (2006), "Representaciones del impacto de la situación de desempleo en las prácticas familiares”, Revista de Psicología Social, 21(3), 241-258. 
American Psychological Association (2015), Stress in America: Paying with our Health. Consultado a 10.03.2015, em https://www.apa.org/news/press/releases/stress/2014/ stress-report.pdf.

Anu, Raijas (2011), "Money Management in Blended and Nuclear Families”, Journal of Economic Psychology, 32, 556-563.

Ashby, Katherine; Burgoyne, Carole (2008), "Separate Financial Entities? Beyond Categories of Money Management”, Journal of Socio-Economics, 37, 458-480.

Atwood, Joan (2012), "Couples and Money: The Last Taboo", The American Journal of Family Therapy, 40, 1-19.

Banco de Portugal (2016), O programa de assistência económica e financeira 2011-2014. Consultado a 24.05.2016, em http://www.bportugal.pt/pt-PT/EstabilidadeFinanceira /OProgramaAssistenciaFinanceiraPortugal/Paginas/PAEFemonitorizacaoposprograma.aspx.

Bennett, Fran (2013), "Researching Within-household Distribution: Overview, Developments, Debates, and Methodological Challenges", Journal of Marriage and Family, 75, 582-597.

Bennett, Fran; De Henau, Jerome; Sung, Sirin (2010), "Within-household inequalities across classes? Management and control of money”, in Jacqueline Scott, Rosemary Crompton, Clare Lyonette (orgs.), Gender Inequalities in the 21st Century: New Barriers and Continuing Constraints. Cheltenham, UK: Edward Elgar, 215-241.

Bisdee, Dinah; Daly, Tom; Price, Debora (2013), "Behind Closed Doors: Older Couples and the Gendered Management of Household Money", Social Policy and Society, 12, 163-174.

Bonke, Jens (2015), "Pooling of Income and Sharing of Consumption within Households", Review of Economics of the Household, 13, 73-93.

Burgoyne, Carole; Clarke, Victoria; Burns, Maree (2011), "Money Management and Views on Civil Partnership in Same-sex Couples: Results from an UK Survey of Non-heterosexuals", Sociological Review, 59, 685-706.

Burgoyne, Carole; Reibstein, Janet; Edmunds, Anne; Dolman, Valda (2007), “Money Management Systems in Early Marriage: Factors Influencing Change and Stability", Journal of Economic Psychology, 28, 214-228.

Cantillon, Sara (2013), "Measuring Differences in Living Standards within Households", Journal of Marriage and Family, 75, 598-610.

Coelho, Lina (2010), Mulheres, família e desigualdade em Portugal. Dissertação para Doutoramento em Economia. Coimbra: Universidade de Coimbra.

Coelho, Lina (2013), "O meu, o teu, o nosso dinheiro: contributos para o estudo da gestão das finanças conjugais em Portugal”, Revista Crítica de Ciências Sociais, 101, 89-110. Coelho, Lina; Ferreira-Valente, Alexandra (2016), "Money and Marriage: Couple's Choices and their Predictors", Revista Española de Investigaciones Sociológicas, 156, 21-40. 
Conger, Rand; Rueter, Martha; Elder, Glen (1999), "Couple Resilience to Economic Pressure”, Journal of Personality and Social Psychology, 76(1), 54-71.

Crenshaw, Kimberle (1989), "Demarginalizing the Intersection of Race and Sex: A Black Feminist Critique of Antidiscrimination Doctrine, Feminist Theory and Antiracist Politics”, University of Chicago Legal Forum, 140, 139-167.

Daly, Mary; Rake, Katherine (2003), Gender and the Welfare State: Care, Work and Welfare in Europe and the USA. Cambridge, Reino Unido: Polity Press/Blackwell.

Deutsch, Francine; Meeske, Cynthia; Roksa, Josipa (2003), "How Gender Counts when Couples Count their Money”, Sex Roles, 48, 291-304.

Elson, Diane (2014), "Economic Crisis from the 1980s to the 2010s: A Gender Analysis”, in Shirin Rai and Georgina Waylen (orgs.), New Frontiers in Feminist Political Economy. London: Routledge, 189-212.

European Commission (2014), Tackling the Gender Pay Gap in the European Union. Luxembourg: Publications Office of the European Union.

Evertsson, Lars; Nyman, Charlott (2012), "Perceptions and Practices in Independent Management: Blurring the Boundaries between 'Mine', 'Yours' and 'Ours'”, Journal of Family Economic Issues, 33, 389-506.

Ferreira, Virgínia (2014), "Employment and Austerity: Changing Welfare and Gender Regimes in Portugal”, in Maria Karamessini e Jill Rubery (org.), Women and Austerity - The Economic Crisis and the Future for Gender Equality. New York: Routledge, 207-227.

Ferreira-Valente, Alexandra; Coelho, Lina (2015a), "Gestão das finanças conjugais em tempo de crise económica”, in Isabel Silva, Marina Pignatelli, Susana Viegas (coords.), Livro de atas do $1 .{ }^{\circ}$ Congresso da Associação Internacional de Ciências Sociais e Humanas em Lingua Portuguesa, 4749-4765.

Ferreira-Valente, Alexandra; Coelho, Lina (2015b), "Salute e crisi economica in Portogallo: uno studio pilota esplorativo”, in Ignazia Bartholini (org.), Radicamenti, discriminazioni e narrazioni di genere nel Mediterraneo. Milano: Franco Angeli, 145-152.

Frade, Catarina; Coelho, Lina (2015), "Surviving the Crisis and Austerity: The Coping Strategies of Portuguese Households”, Indiana Journal of Global Legal Studies, 22(2), 631-664.

Gálvez, Lina; Rodríguez-Modroño, Paula (2012), "La desigualdad de género en las crisis económicas”, Investigaciones Feministas, 2, 113-132.

Gálvez, Lina; Rodríguez-Modroño, Paula (2016), "A Gender Analysis of the Great Recession and 'Austericide' in Spain”, Revista Crítica de Ciências Sociais, 111, 133-152.

Gershuny, Jonathan; Kan, Man (2012), "Halfway to Gender Equality in Paid and Unpaid Work? Evidence from the Multinational Time-use Study", in Jacqueline Scott; Shirley Dex; Anke Plagnol (orgs.), Gendered Lives: Gender Inequalities in Production and Reproduction. Cheltenham: Edward Elgar, 74-94. 
Gomes, Catarina (2000), "Quotidianos conjugais: a decisão financeira como forma de poder”, Forum Sociológico, 34(II Série), 157-178.

Gudmunson, Clinton; Beutler, Ivan; Israelsen, Craig; McCoy, J. Kelly; Hill, E. Jeffrey (2007), "Linking Financial Strain to Marital Instability: Examining the Roles of Emotional Distress and Marital Interaction”, Journal of Family and Economic Issues, 28(3), 357-376.

Heimdal, Kristen; Houseknecht, Sharon (2003), "Cohabiting and Married Couples' Income Organization: Approaches in Sweden and the United States", Journal of Marriage and Family, 65(3), 525-538.

Hoddinott, John; Haddad, Lawrence (1995), "Does Female Income Share Influence Household Expenditures? Evidence from Côte d'Ivoire", Oxford Bulletin of Economics and Statistics, 57(1), 77-96.

Iacovou, Maria; Skew, Alexandra (2011), "Household Composition Across the New Europe: Where do the New Member States fit in?”, Demographic Research, 25, 465-490.

Karamessini, Maria; Rubery, Jill (2014), Women and Austerity - The Economic Crisis and the Future for Gender Equality. London: Routledge.

Kenney, Catherine (2006), "The Power of the Purse: Allocative Systems and Inequality in Couple Households", Gender Society, 20, 354-381.

Kirchler, Erich; Rodler, Christa; Hölzl, Erik; Meier, Katja (2001), Conflict and Decision-making in Close Relationships. Love, Money and Daily Routines. Hove, UK: Psychology Press.

Kirchler, Erich; Winter, Laura; Penz, Elfriede (2016), "Methods of Studying Economic Decisions in Private Households", Revista Crítica de Ciências Sociais, 111, 81-108.

Laporte, Christine; Schellenberg, Grant (2011), "Income Management Strategies of Older Couples in Canada", Canadian Studies in Population, 38(3-4), 1-22.

Laurie, Heather; Gershuny, Jonathan (2000), “Couples, Work and Money”, in Richard Berthoud e Jonathan Gershuny (orgs.), Seven Years in the Lives of British Families: Evidence on the Dynamics of Social Change from the British Housebold Panel Survey. Bristol: Policy Press, 45-72.

Ludwig-Mayerhofer, Wolfgang; Gartner, Hermann; Allmendinger, Jutta (2006), “The Allocation of Money in Couples: The End of Inequality?”, Zeitschrift Für Soziologie, 35(3), 212-226.

Lundberg, Shelly; Startza, Richard; Stillman, Steven (2003), "The Retirement-consumption Puzzle: A Marital Bargaining Approach”, Journal of Public Economics, 87(5-6), 1199-1218.

Lundberg, Shelly; Pollak, Robert; Wales, Terence (1997), "Do Husbands and Wives Pool Their Resources? Evidence from the United Kingdom Child Benefit", The Journal of Human Resources, 32(3), 463-480. 
Madianos, Michael; Economou, Marina; Alexiou, Tatiana; Stefanis, Costas (2011), "Depression and Economic Hardship across Greece in 2008 and 2009: Two Cross-sectional Surveys Nationwide", Social Psychiatry and Psychiatric Epidemiology, 46, 943-952.

Martínez, Capitolina; Méndez, Cecilia; Dema Moreno, Sandra; Pascual, Marta (2004), Amor, dinero e individualidad. Las relaciones económicas en las familias/parejas contemporáneas. Oviedo: KRK Ediciones.

Nagy, Ildikó; Medgyesi, Martón; Lelkes, Orsolya (2012), The 2010 Ad hoc EU SILC module on the intrahousehold sharing of resources, Research Note 3/2012. European Commission: Social Situation Observatory.

Nelson, Julie (1996), Feminism, Objectivity, and Economics. London: Routledge.

Nyman, Charlott; Reinikainen, Lasse; Stocks, Janet (2013), "Reflections on a Cross-national Qualitative Study of Within-household Finances”, Journal of Marriage and Family, 75, 640-650.

Pahl, Jan (1989), Money and Marriage. London: Macmillan.

Pahl, Jan (1995), "His Money, her Money: Recent Research in Financial Organisation in Marriage", Journal of Economic Psychology, 16(3), 361-376.

Pahl, Jan (2000), "Couples and their Money: Patterns of Accounting and Accountability in the Domestic Economy”, Accounting, Auditing and Accountability Journal, 13(4), 502-517.

Pahl, Jan (2005), "Individualisation in Couple Finances: Who Pays for the Children?", Social Policy and Society, 4(4), 381-391.

Pahl, Jan (2007), "Power, Ideology and Resources Within Families: A Theoretical Context for Empirical Research on Sleep”, Sociological Research Online, 12(5), 12. Consultado a 09.10.2009, em http://www.socresonline.org.uk/12/5/12.html.

Pahl, Jan (2008), "Family Finances, Individualisation, Spending Patterns and Access to Credit”, Journal of Socio-Economics, 37, 577-591.

Perista, Heloísa (2002), "Género e trabalho não pago: os tempos das mulheres e os tempos dos homens”, Análise Social, 37(163), 447-474.

Phipps, Shelley; Burton, Peter (1998), "What's Mine is Yours? The Influence of Male and Female Incomes on Patterns of Household Expenditure”, Economica, 65, 599-613.

Poeschl, Gabrielle (2000), "Trabalho doméstico e poder familiar: práticas, normas e ideais”, Análise Social, 35(156), 695-719.

Poeschl, Gabrielle (2016), "Relação de poder entre cônjuges e representações sociais das estratégias de influência no casal”, Revista Crítica de Ciências Sociais, 111, 109-132.

Ribeiro, Raquel; Coelho, Lina; Ferreira-Valente, Alexandra (2015a), "Unemployment and Gender Equality within the Family in Portugal", Ex aequo, 32, 69-85.

Ribeiro, Raquel; Frade, Catarina; Coelho, Lina; Ferreira-Valente, Alexandra (2015b), "Crise económica em Portugal: alterações nas práticas quotidianas e nas relações familiares”, in Isabel Silva, Marina Pignatelli, Susana Viegas (coords.), Livro de atas do $1 .{ }^{\circ}$ Congresso da Associação Internacional de Ciências Sociais e Humanas em Lingua Portuguesa. Lisboa: AICSHLP, 5155-5171. 
Schank, Roger; Abelson, Robert (1975), Scripts, Plans, and Knowledge. New Haven, CT: Yale University.

SEDES (2012), O impacto da crise no bem-estar dos Portugueses. Consultado a 10.03.2015, em http://www.sedes.pt/multimedia/File/SEDES-lcc-Estudo.pdf.

Sen, Amartya (1990), "Gender and Cooperative Conflicts”, in Irene Tinker (org.), Persistent Inequalities: Women and World Development. Oxford: Oxford University Press, 123-149.

Singh, Supriya; Morley, Clive (2011), "Gender and Financial Accounts in Marriage", Journal of Sociology, 47, 3-16.

Sonnenberg, Stefanie (2008), "Household Financial Organisation and Discursive Practice: Managing Money and Identity", Journal of Socio-Economics, 37(2), 533-551.

Thomas, Duncan (1990), "Intrahousehold Resource Allocation: An Inferential Approach”, Journal of Human Resources, 25(4), 635-664.

Thorne, Deborah (2010), "Extreme Financial Strain: Emergent Chores, Gender Inequality and Emotional Distress", Journal of Family and Economic Issues, 31, 185-197.

Vinokur, Amiram; Price, Richard; Caplan, Robert (1996), "Hard Times and Hurtful Partners: How Financial Strain Affects Depression and Relationship Satisfaction of Unemployed Persons and their Spouses”, Journal of Personality and Social Psychology, 71(1), 166-179.

Vogler, Carolyn (1998), "Money in the Household: Some Underlying Issues of Power", The Sociological Review, 46(4), 687-713.

Vogler, Carolyn; Brockmann, Michaela; Wiggins, Richard (2006), "Intimate Relationships and Changing Patterns of Money Management at the Beginning of the Twenty-first Century", The British Journal of Sociology, 57(3), 455-482.

Vogler, Carolyn; Brockmann, Michaela; Wiggins, Richard (2008a), "Managing Money in New Heterosexual Forms of Intimate Relationships", Journal of Socio-Economics, 37(2), 552-576.

Vogler, Carolyn; Lyonette, Clare; Wiggins, Richard (2008b), "Money, Power and Spending Decisions in Intimate Relationships", The Sociological Review, 56(1), 117-143.

Vogler, Carolyn; Pahl, Jan (1993), "Social and Economic Change and the Organization of Money in Marriage”, Work, Employment and Society, 7, 71-95.

Vogler, Carolyn; Pahl, Jan (1994), "Money, Power and Inequality within Marriage”, The Sociological Review, 42(2), 263-289.

Waldfogel, Jane (1998), “The Family Gap for Young Women in the United States and Britain: Can Maternity Leave Make a Difference?”, Journal of Labor Economics, 16(3), 505-545.

Woolley, Frances (2003) "Control over Money in Marriage", in Shoshana Grossbard-Shechtman (org.), Marriage and the Economy: Theory and Evidence from Advanced Industrial Societies. New York: Cambridge University Press, 105-128. 
Zelizer, Viviana (1994), The Social Meaning of Money: Pin Money, Paychecks, Poor Relief, and Other Currencies. New York: Basic Books.

Artigo recebido a 06.06.2016

Aprovado para publicação a 31.08.2016

\section{Lina Coelho}

Centro de Estudos Sociais, Universidade de Coimbra

Colégio de São Jerónimo, Largo D. Dinis, Apartado 3087, 3000-995 Coimbra, Portugal

Contacto: 1coelho@fe.uc.pt

\section{Joint Income, Gender Inequalities and Well-being. Aspects of Portugal in Crisis}

Processes for controlling and managing joint incomes and their implications for allocating resources and well-being within the family are themes in multidisciplinary research that have received a great deal of attention in recent decades, particularly in Anglo-Saxon countries. The literature shows that this is an area of family life in which gender inequalities are particularly evident. This article provides an overview of the subject and the research findings available in the literature, as well as the gaps and methodological limitations. The situation in Portugal is also briefly characterized, based on the results from a recent research project which examined the effects of austerity on multiple aspects of family life, including the material and emotional well-being of men and women. Keywords: austerity; family life; financial management; Portugal; sexual inequality; well-being.

\section{Finances conjugales, inégalités de genre et bien-être. Facettes d'un Portugal en crise}

Les processus de contrôle de gestion de l'argent par le ménage et leurs implications dans la distribution de ressources et de bien-être au sein de la famille sont aujourd'hui un objet de recherche pluridisciplinaire à laquelle a été apportée la plus haute attention au cours des dernières décennies, surtout dans les pays anglo-saxons. Les publications mettent en évidence qu'il s'agit là d'un domaine de la vie familiale où se manifestent, de façon évidente, des inégalités de genre. Cet article caractérise génériquement le thème et les résultats de la recherche disponibles dans les publications, tout autant que leurs lacunes et limitations méthodologiques. La réalité portugaise est elle aussi retracée brièvement en prenant pour base un projet de recherche récent, dans le cadre duquel furent étudiés les effets de l'austérité sur de multiples aspects du vécu familial, y compris le bien-être matériel et émotionnel des hommes et des femmes.

Mots-clés: austérité; bien-être; gestion financière; inégalité sexuelle; Portugal; vie familiale. 